Yüzüncü Yil Üniversitesi
Tarim Bilimleri Dergisi

Araştırma Makalesi (Research Article)

\title{
Batman Merkez İlçede Yetiştirilen Dut Türlerinin Fenolojik, Pomolojik ve Morfolojik Özelliklerinin Belirlenmesi
}

\author{
Sevgi SÜMERLi'1 , Ahmet KAZANKAYA ${ }^{* 2}$ \\ ${ }^{1}$ Van Yüzüncü Y1l Üniversitesi, Ziraat Fakültesi, Bahçe Bitkileri Bölümü, Van, Türkiye \\ ${ }^{2}$ Ahi Evran Üniversitesi, Ziraat Fakültesi, Bahçe Bitkileri Bölümü, Kırşehir, Türkiye \\ ${ }^{1}$ https://orcid.org/0000-0002-9707-8810 2 https://orcid.org/0000-0002-1081-4281 \\ *Sorumlu yazar e-posta: ahmetkazankaya@hotmail.com
}

\section{Makale Bilgileri}

Geliş: 17.04.2020

Kabul: 20.11.2020

Online Yayınlanma 31.12.2020

DOI: 10.29133/yyutbd.722167

\section{Anahtar kelimeler}

Batman,

Dut,

Fenolojik,

Morfolojik,

Pomolojik,
Öz: Bu çalışma 2017-2018 yılları arasında Batman merkez ilçede yetiştiriciliği yapilan Morus alba L., Morus nigra L. ve Morus rubra L. türlerin bazı fenolojik, pomolojik ve morfolojik özelliklerin belirlenmesi amacıyla yürütülmüsstür. Genotiplere ait fenolojik özellikler; tomurcuk patlama zamanı 5-15 Mart, ilk çiçeklenme 20-28 Mart, tam çiçeklenme 13-30 Nisan, hasat başlangıç zamanı 25 Nisan-18 Mayıs, hasat sonu 28 Haziran-10 Ağustos ve yaprak dökümü 10-20 Aralık olarak kaydedilmiştir. Tam çiçeklenmeden hasada kadar geçen süre 85-100 gün arasında belirlenmiştir. Genotiplere ait pomolojik özellikler; meyve çapı 10.17$20.96 \mathrm{~mm}$, boyu 13.30-32.60 mm, sap kalınlığı 0.98-1.69 mm, sap uzunluğu 3.50$23.30 \mathrm{~mm}$, meyve hacmi 8-40 ml (ml/10adet meyve), meyve yoğunluğu 0.45-1.40 $\mathrm{g} / \mathrm{ml}$, meyve ağırlığ $0.54-4.09 \mathrm{~g}$, titre edilebilir asit (TEA) 0.27-0.11 g/100 ml, suda çözünebilir kuru madde miktarı (SÇKM) \%14.10-21,87 ve pH 4.79-7.76 olarak belirlenmiştir. Araştırmaya konu olan genotiplerin morfolojik özellikleri; ağaçların tahmini yaş1 5-100 yıl, gövde yükseklikleri 1.5-4 m, gövde çevresi 35-210 cm, taç yüksekliği 4-15 m, taç genişliği 4-12 m, yıllık sürgün uzunluğu $8.90-18.40 \mathrm{~cm}$ arasında tespit edilmiştir.

\section{Determination of The Phenological, Pomological and Morphological Characteristics of Mulberry Species Grown in Center District of Batman Province}

\section{Article Info}

Received: 17.04 .2020 Accepted: 20.11.2020

Online Published 31.12.2020

DOI: $10.29133 /$ yyutbd.722167

\section{Keywords}

Batman,

Mulbery,

Phenological,

Morphonological,

Pomological.

\begin{abstract}
The aim of this study, carried out 2017-2018, was to determine some phenological, pomological and morphological characteristics of Morus alba L., Morus nigra L. and Morus rubra L. mulberry species grown in the central district of Batman. Phenological characteristics of genotypes; their bud burst time was 5-15 March, first flowering was 20-28 March, while full bloom was 13-30 April, the start time of harvest was 25 April-18 May, in addition, the end of harvest was 28 June10 August and the time of defoliation was recorded as 10-20 December. The period from full bloom to harvest was determined between 85 and 100 days. Pomological characteristics of genotypes; fruit diameter was determined as 10.17-20.96 mm, fruit length was $13.30-32.60 \mathrm{~mm}$, whereas stalk thickness was $0.98-1.69 \mathrm{~mm}$ and stalk length was 3.50-23.30 mm, fruit volume was 8-40 $\mathrm{ml}$ (ml/10 fruit), fruit density was 0.45-1.40 g/ml, fruit weight was 0.54-4.09 g, titratable acid (TEA) 0.27-0.11 g/100 ml, soluble solid content (SSC) \%14.10-21.87 and pH was 4.79-7.76. Morphological features of the genotypes subject to research; the tree's estimated age was found to be 5-100 years, body height to be $1.5-4 \mathrm{~m}$, trunk circumference $35-210 \mathrm{~cm}$, crown height 4-15 m, crown width 4-12 m, whereas annual shoot length was 8.90-18.40 $\mathrm{cm}$.
\end{abstract}

\footnotetext{
**Bu çalışma Yüksek Lisans tezinden türetilmiştir.
} 


\section{Giriş}

Dut; 15 m'ye kadar boylanabilen, hızlı büyüyebilen, silindirik gövdeli, gövde üzerindeki kabuklar dik, kalın ve çatlaklı yapıya sahip, 6-8 metreye ulaşabilen taç yapısına sahip, seyrek ve top görünümlü bir bitkidir. Son zamanlarda sağlı üzerine yapılan çalışmalarla önemi anlaşılan dut, Urticales takımının Moreceae familyasının Morus cinsine dâhil bir meyve türüdür. Moreceae familyasının 73 cinsi, bu cinslerinde, çoğunun sıcak ve tropik bölgelere yayılmış, 100 kadar türü tanımlanmıştır (De Candolle, 1967). Dut, Güney yarım kürenin tropik bölgelerinden Kuzey yarımkürenin subtropik bölgelerine kadar farklı sıcaklıklarda ve çok çeşitli iklim, topografik ve toprak şartlarında yetişebilir. Ayrıca deniz seviyesinden çok yükseklere kadar geniş bir alana yayılmıştır (Ercişli ve Orhan, 2007). Ülkemizde dut ağaçlarının \%95'i M. alba L., \%3’ü M. rubra L. ve \%2'si ise M. nigra L. türüne aittir (Ercişli, 2004). Ülkemizde dut meyvesinden taze ve kurutulmuş olarak yararlanılmaktadır. Meyvesinden pekmez, reçel, dut ezmesi, pestil, cevizli sucuk (köme), sirke, meyve suyu konsantresi, dondurma imalatı, şarap ve ispirto gibi ürünler de elde edilmektedir. Genel olarak dut ülkemizde $\% 70$ pekmez, $\% 10$ köme, $\% 3$ pestil üretiminde, $\% 4$ kuru dut, $\% 5$ de sofralık ve kalan $\% 8$ 'lik oran ise diğer üretim kollarında değerlendirilmektedir (Anonim, 2016). Dut, toprak ve iklim koşulları bakımından fazla seçici olmadığından ülkemizin hemen her yerinde yetiştiriciliği kolaylıkla yapılabilmektedir (Anonim, 2016). Bu çalışmada Batman merkez ilçede yetiştiriciliği yapılan M. alba L., M. nigra L. ve M. rubra L. dut türlerine ait genotiplerin bazı fenolojik, pomolojik ve morfolojik özelliklerin belirlenmesi amaçlanmıştır.

\section{Materyal ve Yöntem}

Bu araştırmanın materyalini, 2017 ve 2018 yıllarında Batman Merkez İlçede yetiştirilen M. alba L., M. nigra L. ve M. rubra L. dut türlerine ait 30 genotip oluşturmuştur. İncelemede her türden 10'ar ağaç işaretlenerek belirlenen ağaçlardan 50'şer adet meyve örneği alınarak gerekli analizler yapılmıştır. Araştırmada, üzerinde çalışılan dut meyvelerin fenolojik, morfolojik, pomolojik ve biyokimyasal özellikleri belirlenmiştir. İlk çiçeklenme zamanı, tam çiçeklenme zamanı, hasat başlangıç zamanı, hasat sonu ve yaprak döküm tarihleri belirlenmiştir. Her genotipten 10 adet y1llık sürgünlerden, sürgün uzunluğu ve sürgün çapı ise $0,01 \mathrm{~mm}$ ye duyarlı dijital kumpasla ölçülerek ortalamaları kaydedilmiştir. Yaprak eni, yaprak boyu, yaprak sap uzunluğu, gövde kalınlığı, yaprak kalınlığı, ağacın taç yüksekliği ve genişliği metre ve cetvel yardımıyla tespit edilmiştir. Meyve sap kalınlığı, meyve sap uzunluğu, SÇKM, TEA (sitrik asit) ve pH değerleri belirlenmiştir (Erdem, 2015). Çalışma sonucunda elde edilen değerlerde istatistik analiz yapılmamış ve sonuçlar ortalama değerler üzerinden ifade edilmiştir.

\section{Bulgular}

\subsection{Fenolojik gözlemler}

Yıllara göre değişmekle birlikte Mart ayının ortasında patlayan tomurcuklardan yaklaşık iki hafta sonra ilk çiçeklenme başlamıştır. İlk meyvelerin hasat olgunluğuna gelmesi Batman koşullarında 2017 yılında 18 Mayıs, 2018 yılında ise 25 Nisan olarak gözlemlenmiştir. Hasat 2017 yılında Ağustos ayının ilk haftasına kadar devam ederken 2018 yılında ise Haziranın sonunda bitmiştir. Ancak meyve yoğunluğu açısından Haziran ayı en fazla meyvenin hasat edildiği dönemdir. Karadut genotiplerinin meyveleri beyaz dut ve mor dut genotiplerinin meyvelerine göre daha geç olgunlaştıkları gözlemlenmiştir.

Çizelge 1. Batman ekolojisindeki genotiplerin bazı fenolojik özellikleri

\begin{tabular}{|c|c|c|}
\hline Fenolojik Safhalar & $2017 \mathrm{y} 11$ & $2018 \mathrm{y} 11$ \\
\hline 1- İlk Çiçeklenme & 28-Mar & 20-Mar \\
\hline 2- Tam Çiçeklenme & 27-30 Nisan & 13-15 Nisan \\
\hline 3- Hasat Başlangıç Zamanı & 18-May & 25-Nis \\
\hline 4- Hasat Sonu & 2-10 Ağustos & 28-30 Haziran \\
\hline 5- Tam Çiçeklenmeden Hasada Kadar Geçen Gün Sayısı & $95-100$ & $85-90$ \\
\hline 6- Yaprak Dökümü & 10-20 Aralık & 15-25 Aralik \\
\hline
\end{tabular}




\subsection{Morfolojik özellikler}

Çalışma sonunda elde edilen verilere göre genotiplerin gövde yüksekliği 1.5-4.0 m arasında, gövde kalınlıkları 35-210 cm arasında bulunmuştur. Taç yüksekliği 4-15 m arasında, taç genişliği 4-12 $\mathrm{m}$ arasında, tahmini yaşı ise 5-100 arasında değiştiği saptanmıştır. 2017 yılında genotiplerin sürgün uzunluğu 8.90-18.40 cm arasında iken 2018 yılında genotiplerin sürgün uzunluğu 4.80-18.20 cm arasında olduğu saptanmıştır.

Çizelge 2. Genotiplerin bazı morfolojik özellikleri

\begin{tabular}{|c|c|c|c|c|c|c|c|c|c|c|c|c|}
\hline & \multirow{2}{*}{ Genotip } & \multirow{2}{*}{$\begin{array}{l}\text { GY } \\
(\mathrm{cm})\end{array}$} & \multirow{2}{*}{$\begin{array}{l}\text { GÇ } \\
(\mathrm{cm})\end{array}$} & \multirow{2}{*}{$\begin{array}{l}\text { TY } \\
\text { (m) }\end{array}$} & \multirow{2}{*}{$\begin{array}{c}\text { ATG } \\
(\mathrm{m})\end{array}$} & \multirow{2}{*}{ ThY } & \multicolumn{3}{|c|}{2017} & \multicolumn{3}{|c|}{2018} \\
\hline & & & & & & & \multicolumn{2}{|c|}{$\mathrm{SU}(\mathrm{cm})$} & SK (cm) & $\mathrm{SU}(\mathrm{cm})$ & & SK $(\mathrm{cm})$ \\
\hline \multirow{10}{*}{ 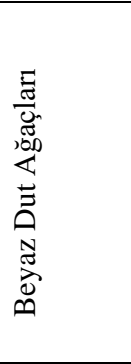 } & B-1 & 150 & 140 & 12 & 8 & 50 & \multicolumn{2}{|c|}{13.90} & 3.19 & 15.80 & & 4.29 \\
\hline & B-2 & 210 & 36 & 6 & 5 & 6 & \multicolumn{2}{|c|}{16.70} & 3.63 & 14.90 & & 3.16 \\
\hline & B-3 & 360 & 80 & 5 & 6 & 40 & \multicolumn{2}{|c|}{18.40} & 3.71 & 18.20 & & 3.73 \\
\hline & B-4 & 400 & 74 & 8 & 11 & 30 & \multicolumn{2}{|c|}{17.30} & 2.97 & 12.40 & & 2.54 \\
\hline & B-5 & 200 & 95 & 7 & 5 & 30 & \multicolumn{2}{|c|}{14.60} & 3.78 & 11.40 & & 3.68 \\
\hline & B-6 & 285 & 90 & 5 & 4 & 25 & \multicolumn{2}{|c|}{11.60} & 2.80 & 12.20 & & 2.87 \\
\hline & B-7 & 175 & 140 & 7 & 6 & 45 & \multicolumn{2}{|c|}{12.50} & 2.64 & 12.90 & & 2.66 \\
\hline & B-8 & 285 & 60 & 5 & 4 & 15 & \multicolumn{2}{|c|}{13.00} & 3.23 & 13.60 & & 3.39 \\
\hline & B-9 & 340 & 210 & 9 & 8 & 100 & \multicolumn{2}{|c|}{14.40} & 2.72 & 15.30 & & 2.95 \\
\hline & B-10 & 290 & 120 & 12 & 10 & 50 & \multicolumn{2}{|c|}{9.30} & 3.31 & 9.90 & & 3.12 \\
\hline Ortalama & & 269 & 104 & 7.6 & 6.7 & 39.1 & & & 3.198 & 13.66 & & 3.239 \\
\hline & K-11 & 170 & 83 & 7 & 6 & 25 & & & 3.28 & 10.40 & & 2.71 \\
\hline & K-12 & 220 & 87 & 8 & 5 & 30 & & & 4.77 & 13.30 & & 3.08 \\
\hline$\frac{\pi}{0}$ & K-13 & 270 & 68 & 7 & 6 & 20 & & & 4.17 & 11.00 & & 2.67 \\
\hline 趈 & K-14 & 275 & 45 & 5 & 4 & 13 & & & 2.95 & 11.40 & & 2.91 \\
\hline$\stackrel{\rightleftarrows}{=}$ & K-15 & 235 & 45 & 4 & 4 & 10 & & & 2.93 & 11.90 & & 2.96 \\
\hline$\overline{\bar{\partial}}$ & K-16 & 180 & 80 & 15 & 8 & 20 & & & 3.34 & 11.70 & & 2.70 \\
\hline$\overline{\vec{v}}$ & K-17 & 230 & 160 & 15 & 12 & 80 & & & 2.09 & 11.30 & & 2.20 \\
\hline $\bar{\Xi}$ & K-18 & 225 & 80 & 5 & 5 & 20 & & & 3.12 & 12.10 & & 3.36 \\
\hline & K-19 & 335 & 115 & 7 & 6 & 50 & & & 3.65 & 11.60 & & 3.69 \\
\hline & K-20 & 225 & 75 & 6 & 6 & 15 & & & 2.64 & 11.00 & & 2.85 \\
\hline Ortalama & & 236.5 & 83.8 & 7.9 & 6.2 & 28.3 & & & 3.294 & 11.57 & & 2.913 \\
\hline & M-21 & 198 & 70 & 5 & 5 & 10 & & & 2.87 & 12.11 & & 2.70 \\
\hline & M-22 & 400 & 85 & 15 & 9 & 40 & & & 1.87 & 4.80 & & 2.28 \\
\hline $\bar{\Xi}$ & M-23 & 180 & 35 & 8 & 6 & 5 & & & 1.88 & 11.10 & & 1.99 \\
\hline 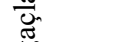 & M-24 & 235 & 130 & 5 & 5 & 40 & & & 2.35 & 13.40 & & 2.68 \\
\hline$\underset{<}{1000}$ & M-25 & 175 & 110 & 8 & 7 & 35 & & & 2.77 & 11.60 & & 3.04 \\
\hline$\equiv$ & M-26 & 210 & 105 & 7 & 6 & 25 & & & 2.40 & 11.10 & & 2.77 \\
\hline 9 & M-27 & 270 & 95 & 9 & 12 & 30 & & & 3.08 & 9.30 & & 3.19 \\
\hline$\stackrel{5}{s}$ & M-28 & 165 & 85 & 5 & 6 & 25 & & & 2.33 & 10.40 & & 2.63 \\
\hline & M-29 & 250 & 100 & 15 & 8 & 30 & & & 2.29 & 9.70 & & 2.48 \\
\hline & M-30 & 160 & 45 & 7 & 6 & 8 & & & 2.38 & 12.90 & & 2.40 \\
\hline Ortalama & & 224.3 & 86 & 8.4 & 7 & 24.8 & & & 2.422 & 10.641 & & 2.616 \\
\hline & B-1 & 8.75 & 12.20 & 0.35 & & & 2.30 & 10.66 & 14.84 & 0.33 & 3.14 & 2.19 \\
\hline & B-2 & 6.90 & 9.90 & 0.41 & & & 1.80 & 6.97 & 10.13 & 0.29 & 3.35 & 1.75 \\
\hline$\frac{\pi}{0}$ & B-3 & 9.80 & 10.85 & 0.36 & & & 2.43 & 9.81 & 13.05 & 0.37 & 3.52 & 2.28 \\
\hline 趈 & B-4 & 7.40 & 11.85 & 0.32 & & & 1.71 & 7.55 & 12.02 & 0.34 & 3.50 & 1.78 \\
\hline 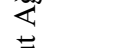 & B-5 & 9.35 & 13.65 & 0.38 & & & 2.29 & 9.95 & 13.71 & 0.39 & 4.80 & 2.28 \\
\hline $\overrightarrow{\vec{\theta}}$ & B-6 & 9.98 & 15.50 & 0.42 & & & 2.60 & 10.25 & 15.90 & 0.42 & 4.30 & 2.73 \\
\hline స్ & B-7 & 10.20 & 11.42 & 0.40 & & & 2.63 & 10.80 & 13.17 & 0.40 & 3.95 & 2.70 \\
\hline స్త & B-8 & 6.61 & 9.19 & 0.39 & & & 1.80 & 6.65 & 9.63 & 0.35 & 2.78 & 1.79 \\
\hline & B-9 & 7.24 & 10.13 & 0.40 & & & 2.16 & 7.21 & 10.19 & 0.39 & 3.87 & 2.23 \\
\hline & B-10 & 8.38 & 10.95 & 0.39 & & & 2.15 & 7.23 & 11.15 & 0.39 & 2.90 & 2.23 \\
\hline
\end{tabular}

GY: Gövde Yüksekliği (cm), GÇ: Gövde Çevresi (cm), TY: Taç Yüksekliği (m), ATG: Ağaç Taç Genişliği (m), ThY: Tahmini Yaş, SU: Sürgün Uzunluğu (cm), SK: Sürgün Kalınlığı $(\mathrm{cm})$. 
Çizelge 2. Genotiplerin bazı morfolojik özellikleri (devam)

\begin{tabular}{lllllllllll}
\hline & \multicolumn{1}{c}{2017} & \multicolumn{1}{c}{2018} \\
\cline { 2 - 10 } Genotip & YE & YB & YK & YSU & YSK & YE & YB & YK & YSU & $\begin{array}{c}\text { YSK } \\
(\mathrm{mm})\end{array}$ \\
\hline
\end{tabular}

\begin{tabular}{|c|c|c|c|c|c|c|c|c|c|c|c|}
\hline Ortalama & & 8.461 & 11.564 & 0.382 & 3.579 & 2.187 & 8.708 & 12.379 & 0.367 & 3.611 & 2.196 \\
\hline \multirow{10}{*}{ 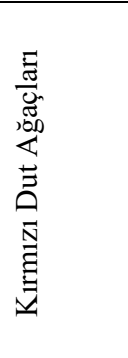 } & K-11 & 7.80 & 11.50 & 0.28 & 3.25 & 1.80 & 8.35 & 11.50 & 0.32 & 3.30 & 1.85 \\
\hline & $\mathrm{K}-12$ & 5.50 & 8.75 & 0.35 & 2.80 & 1.82 & 6.30 & 8.75 & 0.36 & 3.10 & 1.88 \\
\hline & $\mathrm{K}-13$ & 9.41 & 13.30 & 0.39 & 4.17 & 2.44 & 9.23 & 13.05 & 0.40 & 4.32 & 2.42 \\
\hline & $\mathrm{K}-14$ & 8.60 & 11.05 & 0.40 & 3.11 & 2.34 & 8.87 & 12.65 & 0.39 & 3.25 & 2.29 \\
\hline & $\mathrm{K}-15$ & 8.35 & 11.94 & 0.36 & 3.51 & 2.28 & 8.35 & 12.73 & 0.36 & 3.59 & 2.36 \\
\hline & $\mathrm{K}-16$ & 11.69 & 15.26 & 0.41 & 4.45 & 2.91 & 12.10 & 15.15 & 0.40 & 4.50 & 2.98 \\
\hline & $\mathrm{K}-17$ & 9.85 & 13.20 & 0.37 & 3.58 & 2.30 & 10.07 & 13.49 & 0.37 & 3.67 & 2.21 \\
\hline & $\mathrm{K}-18$ & 6.87 & 9.42 & 0.53 & 2.58 & 2.11 & 7.18 & 9.77 & 0.37 & 2.78 & 2.15 \\
\hline & $\mathrm{K}-19$ & 10.27 & 12.85 & 0.35 & 2.67 & 2.42 & 10.85 & 12.21 & 0.34 & 2.76 & 2.74 \\
\hline & $\mathrm{K}-20$ & 7.70 & 11.10 & 0.38 & 3.47 & 2.11 & 7.84 & 11.35 & 0.40 & 3.21 & 2.22 \\
\hline Ortalama & & 8.604 & 11.837 & 0.382 & 3.359 & 2.253 & 8.914 & 12.065 & 0.371 & 3.448 & 2.31 \\
\hline \multirow{10}{*}{ 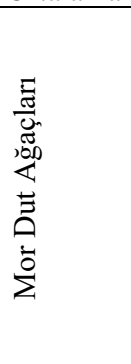 } & M-21 & 8.90 & 11.85 & 0.31 & 4.53 & 2.06 & 9.15 & 12.65 & 0.32 & 3.85 & 2.16 \\
\hline & M-22 & 3.91 & 6.83 & 0.37 & 2.59 & 1.39 & 4.95 & 6.63 & 0.38 & 2.84 & 1.42 \\
\hline & M-23 & 8.07 & 12.41 & 0.37 & 2.37 & 2.15 & 8.38 & 12.70 & 0.38 & 2.79 & 2.22 \\
\hline & M-24 & 7.10 & 11.80 & 0.41 & 3.40 & 2.13 & 7.42 & 11.90 & 0.41 & 3.57 & 2.17 \\
\hline & M-25 & 7.71 & 10.92 & 0.36 & 3.80 & 2.13 & 8.17 & 11.50 & 0.39 & 3.75 & 2.21 \\
\hline & M-26 & 7.45 & 11.50 & 0.41 & 3.45 & 2.11 & 7.60 & 12.00 & 0.42 & 3.50 & 2.17 \\
\hline & M-27 & 8.48 & 12.15 & 0.37 & 3.71 & 2.34 & 8.61 & 12.28 & 0.37 & 3.86 & 2.36 \\
\hline & M-28 & 7.21 & 11.20 & 0.39 & 3.40 & 2.00 & 7.46 & 11.90 & 0.39 & 3.48 & 2.10 \\
\hline & M-29 & 6.40 & 10.05 & 0.43 & 2.85 & 1.83 & 6.56 & 9.85 & 0.42 & 3.00 & 1.76 \\
\hline & M-30 & 8.91 & 13.02 & 0.30 & 3.52 & 2.22 & 8.75 & 13.07 & 0.29 & 3.52 & 2.17 \\
\hline Ortalama & & 7.414 & 11.173 & 0.372 & 3.362 & 2.036 & 7.705 & 11.448 & 0.377 & 3.416 & 2.074 \\
\hline
\end{tabular}

YE: Yaprak Eni (cm), YB: Yaprak Boyu (cm), YK: Yaprak Kalınlığı (mm), YSU: Yaprak Sap Uzunluğu (cm), YSK: Yaprak Sap Kalınlığı (mm)

\subsection{Pomolojik özellikler}

2017 yılına ait genotiplerin ağırlıkları 0.54-4.09 g arasında değiştiği görülmektedir. Kırmızı dut genotiplerinin ortalama meyve ağırlığı beyaz ve mor dut genotiplerine oranla daha yüksek, beyaz dut genotiplerinin ortalama meyve ağırlığ 1 ise mor dut genotiplerinden fazla olduğu tespit edilmiştir. 2017 yılına ait dut genotiplerinin meyve çapı 10.21-17.42 mm arasında, meyve boyu ise 14.10-30.40 mm arasında değişmiştir. 2018 yılına ait dut genotiplerinin meyve çapı 10.17-20.96 mm aralığında, meyve boyu ise 13.30-32.60 $\mathrm{mm}$ aralı̆̆ındadır. 
Çizelge 3. Genotiplerinin bazı pomolojik özellikleri

\begin{tabular}{|c|c|c|c|c|c|c|c|c|c|c|c|c|c|}
\hline & \multirow[b]{2}{*}{ Genotip } & \multicolumn{6}{|c|}{2017} & \multicolumn{6}{|c|}{2018} \\
\hline & & $\begin{array}{c}\text { MÇ } \\
(\mathrm{mm})\end{array}$ & $\begin{array}{c}\mathrm{MB} \\
(\mathrm{mm})\end{array}$ & $\begin{array}{l}\text { MSK } \\
(\mathrm{mm})\end{array}$ & $\begin{array}{l}\text { MSU } \\
(\mathrm{mm})\end{array}$ & $\begin{array}{l}\mathrm{MH} \\
(\mathrm{ml})\end{array}$ & $\begin{array}{c}\mathrm{MY} \\
(\mathrm{g} / \mathrm{ml})\end{array}$ & $\begin{array}{c}\text { MÇ } \\
\text { (mm) }\end{array}$ & $\begin{array}{c}\mathrm{MB} \\
(\mathrm{mm})\end{array}$ & $\begin{array}{l}\text { MSK } \\
(\mathrm{mm})\end{array}$ & $\begin{array}{l}\text { MSU } \\
(\mathrm{mm})\end{array}$ & $\begin{array}{l}\mathrm{MH} \\
(\mathrm{ml})\end{array}$ & $\begin{array}{c}\mathrm{MY} \\
(\mathrm{g} / \mathrm{ml})\end{array}$ \\
\hline \multirow{10}{*}{ 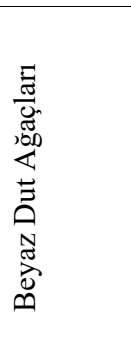 } & B-1 & 12.97 & 19.80 & 1.27 & 10.30 & 22 & 0.90 & 13.07 & 20.40 & 1.27 & 10.30 & 23 & 0.91 \\
\hline & B-2 & 12.61 & 17.50 & 1.07 & 7.80 & 15 & 0.80 & 14.09 & 22.90 & 1.07 & 7.80 & 20 & 1.15 \\
\hline & B-3 & 14.46 & 26.10 & 1.30 & 9.30 & 30 & 0.93 & 15.39 & 26.20 & 1.30 & 9.30 & 30 & 0.90 \\
\hline & B-4 & 12.94 & 19.90 & 1.24 & 6.90 & 15 & 1.03 & 13.02 & 20.70 & 1.24 & 6.90 & 17 & 1.03 \\
\hline & B-5 & 15.06 & 25.20 & 1.39 & 10.90 & 30 & 0.90 & 15.01 & 25.60 & 1.39 & 10.90 & 30 & 1.12 \\
\hline & B-6 & 16.31 & 24.90 & 1.54 & 5.00 & 35 & 0.85 & 13.03 & 22.80 & 1.54 & 5.00 & 20 & 0.94 \\
\hline & B-7 & 15.07 & 26.30 & 1.31 & 10.20 & 30 & 0.93 & 13.84 & 23.30 & 1.31 & 10.20 & 20 & 1.03 \\
\hline & B-8 & 13.86 & 24.00 & 1.16 & 7.30 & 25 & 0.92 & 13.17 & 22.10 & 1.16 & 7.30 & 20 & 0.90 \\
\hline & B-9 & 13.53 & 23.80 & 1.47 & 3.50 & 20 & 1.03 & 13.33 & 27.80 & 1.47 & 3.50 & 30 & 1.09 \\
\hline & B-10 & 14.39 & 25.80 & 1.38 & 11.80 & 25 & 0.92 & 13.02 & 23.90 & 1.38 & 11.80 & 20 & 0.96 \\
\hline Ortalama & & 14.12 & 23.33 & 1.313 & 8.3 & 24.7 & 0.921 & 13.697 & 23.57 & 1.313 & 8 & 23 & 1.003 \\
\hline \multirow{10}{*}{ 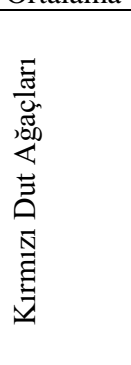 } & K-11 & 13.04 & 30.40 & 1.30 & 7.70 & 20 & 1.20 & 13.06 & 29.10 & 1.30 & 7.70 & 20 & 1.12 \\
\hline & $\mathrm{K}-12$ & 13.23 & 22.60 & 1.56 & 5.70 & 25 & 0.80 & 13.38 & 21.70 & 1.56 & 5.70 & 29 & 0.89 \\
\hline & K-13 & 17.25 & 26.40 & 1.55 & 8.70 & 40 & 0.95 & 16.78 & 25.80 & 1.55 & 8.70 & 40 & 0.94 \\
\hline & K-14 & 13.24 & 21.00 & 1.20 & 12.20 & 20 & 0.85 & 14.64 & 19.80 & 1.20 & 12.20 & 20 & 1.02 \\
\hline & K-15 & 14.28 & 26.20 & 1.41 & 13.70 & 30 & 0.90 & 12.73 & 26.10 & 1.41 & 13.70 & 22 & 1.12 \\
\hline & K-16 & 14.54 & 25.80 & 1.21 & 10.90 & 28 & 0.92 & 14.11 & 32.60 & 1.21 & 10.90 & 30 & 1.08 \\
\hline & K-17 & 13.68 & 24.00 & 1.33 & 10.80 & 15 & 0.45 & 13.37 & 24.50 & 1.33 & 10.80 & 20 & 0.90 \\
\hline & K-18 & 16.40 & 30.20 & 1.69 & 7.70 & 40 & 0.92 & 13.16 & 27.80 & 1.69 & 7.70 & 25 & 1.06 \\
\hline & K-19 & 17.42 & 27.50 & 1.60 & 3.50 & 40 & 1.00 & 20.96 & 30.70 & 1.60 & 3.50 & 38 & 1.00 \\
\hline & K-20 & 14.68 & 23.60 & 1.33 & 7.00 & 25 & 0.94 & 14.26 & 24.30 & 1.33 & 7.00 & 20 & 1.22 \\
\hline Ortalama & & 14.776 & 25.77 & 1.418 & 8.79 & 28.3 & 0.893 & 14.645 & 26.24 & 1.418 & 8.79 & 26.4 & 1.035 \\
\hline \multirow{10}{*}{ 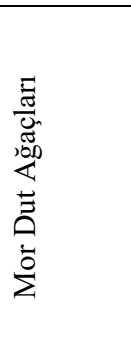 } & M-21 & 15.08 & 23.00 & 1.16 & 23.30 & 31 & 0.77 & 14.13 & 23.70 & 1.16 & 23.30 & 25 & 1.08 \\
\hline & M-22 & 10.21 & 14.30 & 0.98 & 5.30 & 8 & 0.87 & 10.17 & 13.30 & 0.98 & 5.30 & 9 & 0.86 \\
\hline & M-23 & 11.67 & 17.60 & 1.37 & 8.00 & 15 & 0.78 & 12.41 & 19.70 & 1.37 & 8.00 & 20 & 0.70 \\
\hline & M-24 & 14.53 & 25.40 & 1.69 & 5.00 & 27 & 0.96 & 15.73 & 27.10 & 1.69 & 5.00 & 30 & 1.10 \\
\hline & M-25 & 14.20 & 25.20 & 1.36 & 6.80 & 26 & 0.98 & 16.04 & 26.10 & 1.36 & 6.80 & 25 & 1.04 \\
\hline & M-26 & 14.28 & 23.50 & 1.20 & 12.70 & 25 & 1.04 & 15.41 & 27.20 & 1.20 & 12.70 & 30 & 1.10 \\
\hline & M-27 & 13.73 & 20.20 & 1.26 & 6.90 & 17 & 0.98 & 13.45 & 19.90 & 1.26 & 6.90 & 17 & 1.06 \\
\hline & M-28 & 15.07 & 24.20 & 1.11 & 10.50 & 30 & 0.80 & 11.65 & 17.80 & 1.11 & 10.50 & 10 & 1.20 \\
\hline & M-29 & 12.32 & 14.10 & 1.07 & 5.80 & 12 & 1.04 & 11.55 & 22.00 & 1.07 & 5.80 & 10 & 1.40 \\
\hline & M-30 & 12.47 & 19.30 & 1.01 & 6.00 & 15 & 0.84 & 12.38 & 19.00 & 1.01 & 6.00 & 14 & 0.92 \\
\hline Ortalama & & 13.356 & 20.68 & 1.221 & 9.03 & 20.6 & 0.906 & 13.292 & 21.58 & 1.221 & 9.03 & 19 & 1.046 \\
\hline
\end{tabular}

MSK: Meyve Sap Kalınlığı (mm), MSU: Meyve Sap Uzunluğu (mm), MH: Meyve Hacmi (ml), MY: Meyve Yoğunluğu (g/ml), MB: Meyve Boyu 
Çizelge 4. Genotiplerin bazı biyokimyasal içerikleri

\begin{tabular}{|c|c|c|c|c|c|c|c|c|c|}
\hline & \multirow{2}{*}{ Genotip } & \multicolumn{2}{|c|}{ Ăğılık (g) } & \multicolumn{2}{|c|}{ SÇKM (\%) } & \multicolumn{2}{|c|}{$\overline{\mathrm{pH}}$} & \multicolumn{2}{|c|}{ TEA } \\
\hline & & 2017 & 2018 & 2017 & 2018 & 2017 & 2018 & 2017 & 2018 \\
\hline \multirow{10}{*}{ 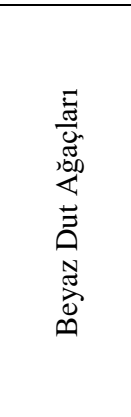 } & B-1 & 1.91 & 2.09 & 18.55 & 19.20 & 5.86 & 6.23 & 0.19 & 0.20 \\
\hline & B-2 & 1.24 & 2.30 & 20.12 & 20.81 & 5.92 & 6.40 & 0.21 & 0.22 \\
\hline & B-3 & 2.80 & 2.73 & 18.70 & 18.80 & 6.00 & 6.05 & 0.17 & 0.16 \\
\hline & B-4 & 1.57 & 1.79 & 20.60 & 21.87 & 6.10 & 6.82 & 0.18 & 0.19 \\
\hline & B-5 & 2.74 & 3.38 & 19.12 & 18.53 & 5.85 & 6.16 & 0.24 & 0.27 \\
\hline & B-6 & 3.06 & 1.87 & 18.80 & 19.65 & 5.80 & 5.82 & 0.23 & 0.25 \\
\hline & B-7 & 2.63 & 2.14 & 20.36 & 21.05 & 6.10 & 6.14 & 0.19 & 0.11 \\
\hline & B-8 & 2.38 & 1.79 & 19.86 & 20.17 & 6.25 & 6.33 & 0.17 & 0.16 \\
\hline & B-9 & 2.02 & 3.26 & 20.46 & 20.35 & 5.75 & 6.02 & 0.21 & 0.22 \\
\hline & B-10 & 2.42 & 1.89 & 19.20 & 19.00 & 5.82 & 5.86 & 0.23 & 0.23 \\
\hline Ortalama & & 2.28 & 2.32 & 19.58 & 19.94 & 5.95 & 6.18 & 0.20 & 0.20 \\
\hline \multirow{10}{*}{ 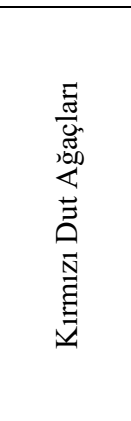 } & K-11 & 2.39 & 2.26 & 17.55 & 17.42 & 5.40 & 5.12 & 0.19 & 0.18 \\
\hline & K-12 & 2.01 & 2.51 & 16.20 & 15.40 & 5.14 & 4.79 & 0.17 & 0.16 \\
\hline & K-13 & 3.84 & 3.76 & 16.50 & 16.27 & 5.26 & 5.55 & 0.18 & 0.19 \\
\hline & K-14 & 1.71 & 2.06 & 18.15 & 18.6 & 6.05 & 6.11 & 0.18 & 0.17 \\
\hline & K-15 & 2.78 & 2.46 & 18.30 & 17.84 & 5.49 & 5.30 & 0.17 & 0.17 \\
\hline & K-16 & 2.60 & 3.26 & 19.20 & 18.12 & 5.00 & 5.04 & 0.12 & 0.11 \\
\hline & K-17 & 2.03 & 1.94 & 17.50 & 14.34 & 5.30 & 5.24 & 0.18 & 0.16 \\
\hline & K-18 & 3.69 & 2.59 & 18.10 & 17.40 & 5.52 & 5.79 & 0.21 & 0.22 \\
\hline & K-19 & 4.09 & 3.97 & 19.00 & 18.64 & 5.75 & 6.00 & 0.23 & 0.23 \\
\hline & K-20 & 2.37 & 2.45 & 17.30 & 16.28 & 5.60 & 5.59 & 0.18 & 0.18 \\
\hline Ortalama & & 2.75 & 2.73 & 17.78 & 17.03 & 5.45 & 5.45 & 0.18 & 0.18 \\
\hline \multirow{10}{*}{ 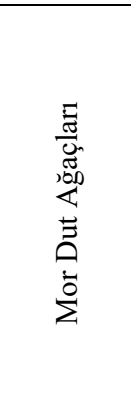 } & M-21 & 2.33 & 2.73 & 18.12 & 17.30 & 5.81 & 6.25 & 0.18 & 0.19 \\
\hline & M-22 & 0.54 & 0.58 & 16.25 & 14.10 & 6.52 & 7.15 & 0.17 & 0.16 \\
\hline & M-23 & 1.22 & 1.40 & 18.56 & 18.80 & 6.20 & 6.31 & 0.21 & 0.21 \\
\hline & M-24 & 2.64 & 3.34 & 18.42 & 18.30 & 6.60 & 7.35 & 0.20 & 0.22 \\
\hline & M-25 & 2.59 & 2.66 & 19.20 & 19.30 & 6.24 & 6.57 & 0.22 & 0.21 \\
\hline & M-26 & 2.63 & 3.34 & 15.78 & 14.50 & 6.75 & 7.28 & 0.18 & 0.17 \\
\hline & M-27 & 1.68 & 2.09 & 20.05 & 19.90 & 6.60 & 6.81 & 0.23 & 0.26 \\
\hline & M-28 & 2.39 & 1.18 & 19.00 & 19.14 & 6.74 & 7.76 & 0.24 & 0.24 \\
\hline & M-29 & 1.26 & 1.48 & 16.16 & 15.84 & 5.38 & 5.54 & 0.18 & 0.13 \\
\hline & M-30 & 1.29 & 1.31 & 15.1 & 14.22 & 5.86 & 6.00 & 0.17 & 0.16 \\
\hline Ortalama & & 1.86 & 2.01 & 17.67 & 17.14 & 6.27 & 6.70 & 0.20 & 0.20 \\
\hline
\end{tabular}

\section{Tartışma ve Sonuç}

Fenolojik özellikleri açısından; tomurcuk patlama zamanı 5-15 Mart, ilk çiçeklenme 20-28 Mart, tam çiçeklenme 13-30 Nisan, hasat başlangıç zamanı 25 Nisan-18 Mayıs, hasat sonu 28 Haziran10 Ağustos, tam çiçeklenmeden hasada kadar geçen gün sayıs1 85-100 ve yaprak dökümü 10-20 Aralık olarak kaydedilmiştir. Van'da yapılan bir çalışmada tomurcuk kabarma tarihleri 5-17 Mayıs, tomurcukların patlama tarihleri 6-18 Mayıs, çiçeklenme tarihleri 20 Mayıs-3 Haziran ve meyvelerin olgunlaşmaya başladığı periyot 18 Haziran-10 Temmuz tarihleri arasında bulunmuştur (Çam, 2004). İzmir'de yapılan diğer bir çalışmada ise tomurcuk kabarmasının Nisan ayının ilk haftası, meyvelerin hasada başlama tarihi Mayıs ayı sonları olarak belirlemiştir (Lale, 1992). Yaprak ölçümlerine ait verilerde yaprak eni 3.91-11.69 cm, yaprak boyu 6.63-15.90 cm, yaprak kalınlığı 0.28-0.53 mm, yaprak sap uzunluğu 2.28-4.80 cm ve yaprak sap kalınlığ 1.39-2.98 mm arasında olduğu tespit edilmiştir. Uzun ve Bayır (2009) dut yapraklarında yapılan ölçümlerde ortalama yaprak enini $84.4 \mathrm{~mm}$, yaprak boyunu $105.3 \mathrm{~mm}$ ve yaprak sap uzunluğunu $28.70 \mathrm{~mm}$ olarak ölçmüştür. Ilgın ve Ağca (2017) dut yapraklarında sap uzunluğunun 37.60-26.74 mm arasında değiştiğini ortaya koymuştur. Bu denemedeki yaprak ölçümlerine ait veriler incelendiğinde Uzun ve Bayır (2009) ve Ilgın ve Ağca (2017)'nın yapmış oldukları çalışmayla uyumlu olduğu gözlemlenmiştir.

Meyve ağırlığının 0.54-4.09 g arasında değiştiği tespit edilmiştir. Yapılan çalışmalarda Çam (2004) 1.38-2.62 g, Aslan (1998) 1.46-2.32 g, Özgen ve ark. (2009) 8.2-4.5 g. Uzun ve Bayır (2009) 
2.35-5.76 g, İslam ve ark. (2006) 2.12-4.72 g, Güneş ve Çekiç (2003) 3.02-8.70 g arasında değiştiğini belirlemişlerdir. Elde edilen sonuçlar Çam (2004) ve Aslan (1998)'ın yaptıkları çalışmalardaki meyvelerden daha ağır, İslam ve ark (2006)'nın çalışmalarındaki meyveler ile paralel iken, Özgen ve ark (2009), Uzun ve Bayır (2009) ve Güneş ve Çekiç (2003)'in çalışmalarına oranla daha düşük olduğu görülmüştür. Meyve çapı 10.17-20.96 mm, meyve boyu 13.30-32.60 mm, meyve sap kalınlığı 0.98-1.69 $\mathrm{mm}$ ve meyve sap uzunluğu 3.50-23.30 mm arasında değiştiği gözlemlenmiştir. Van Gölü havzasında yapılan bir çalışmada meyve eni $6.65-10.11 \mathrm{~mm}$, meyve boyu ise 12.66-19.52 mm arasında değiştiği (Gündoğdu ve ark. 2012), Uzun ve Bayır (2009)'ın karadut ağaçlarında yaptıkları çalışmada meyve eni 13.5-19.6 mm, meyve boyu 20.9-25.4 mm arasında değiştiğ i, Ulubey ilçesinde yapılan çalışmada ise karadut meyvelerin enleri $13.037-16.567 \mathrm{~mm}$ arasinda, boyları ise $16.703-23.473 \mathrm{~mm}$ arasinda değiştiği (Erkaleli, 2015) araştırmacılar tarafından kaydedilmiştir. Elde edilen sonuçlar; Uzun ve Bayır (2009) ve Erkaleli (2015)'in yapmış oldukları çalışmalarla paralel sonuçlar ortaya koyduğu belirlenmiştir.

Genotiplerin TEA miktarı (sitrik asit olarak) 2017 yılında 0.12-0.24, 2018 yılında ise 0.11-0.27 g/100 ml, SÇKM miktarı 2017 yılında \%15.10-20.60, 2018 y1lında \%14.10-21,87 ve pH miktarı 2017 yılında 5.00-6.75, 2018 yılında ise 4.79-7.76 arasında değiştiği saptanmıştır. Çam (2004) pH değeri miktarının 6.2-7.4, SÇKM miktarının 16.62-19.16 ve TA miktarının 0.167-0.264 arasında, Polat (2005) SÇKM miktarının 13.73-16.01, pH miktarının 4.39-6.16 ve TA miktarının 0.06-1.00, Lale (1992) pH miktarının 3.31, SÇKM miktarının 14.30, TA miktarının 2.24, Uzun ve Bayır (2009) pH miktarının 3.33.8, SKÇM miktarının 15.6-17.6 ve TA miktarının 1.94-2.23 arasında değiştiğini saptamışlardır. Elde edilen sonuçların pH değeri, Çam (2004) ve Polat (2005)'ın elde ettiği sonuçlarla paralellik gösterirken, Lale (1992) ve Uzun ve Bayır (2009)'ın yapmış oldukları çalışmadan daha yükssek olduğu tespit edilmiştir. Ayrıca SÇKM değeri açısından bu çalışmanın sonuçları Çam (2004), Uzun ve Bayır (2009), Polat (2005) ve Lale (1992)'nin çalışmalarının sonuçları ile uyumlu olduğu, TEA değeri açısından ise Polat (2005)'ın yaptığı çalışmadan yüksek, Uzun ve Bayır (2009), Çam (2004) ve Lale (1992)'nin yaptığı çalışma ile paralel olduğu görülmüştür. Dut genotipleri üzerine yapılan birçok çalışmada görüldüğü gibi, sonuçlar üzerinde farklı tür, iklim, ekoloji ve çevresel faktörler etki etmektedir.

\section{Teşekkür}

Maddi desteğinden dolayı Yüzüncü Y1l Üniversitesi, Bilimsel Araştırma Projeleri Başkanlığı'na (Proje No: FYL-2017-6100) teşekkür ederiz.

\section{Kaynakça}

Anonim, (2016). http://tarimsalistatistik.com/tr-TR/Sayfa/dut-yetistiriciligi. Erişim tarihi: 11.01.2016.

Aslan, M. M. (1998). Malatya, Elazı̆̆, Erzincan ve Tunceli İllerine Bağlı Bazı İlçelerden Ümitvar Dut Tiplerinin Seçimi. Çukurova Üniversitesi, Adana.

Çam, İ. (2004). Edremit ve Gevaş yöresi dutlarının bazı fenolojik ve pomolojik özellikleri. Yüzüncü Yıl Üniversitesi Ziraat Fakültesi, Tarım Bilimleri Dergisi (YYUJAGRSCI). 14(2), 127-131.

De Candolle, A. (1967). Origin Of Cultivated Plants. New Yok and London. P 149-153.

Erdem, S. (2015). Bulancak karası dutunun bazı meyve özelliklerinin belirlenmesi ve çelikle çoğaltılması üzerine bir araştırma. (Yüksek Lisans Tezi). Ordu Üniversitesi, Fen Bilimleri Enstitüsü, Bahçe Bitkileri Anabilim Dal1, 38s.

Erdoğan, Ü., \& Pırlak, L. (2005). Ükemizde dut (Morus spp.) üretimi ve değerlendirilmesi, Alatarım. $4(2), 38-43$.

Ercişli, S., \& Orhan, E. (2007). Chemical composition of white, red and black mulberry fruits. Food Chemistry. 103(4), 1380-1384.

Ercişli, S. (2004). A short review of the fruit germplasm resources of Turkey. Genetic Resources and Crop Evolution. 51 (4), 419-435.

Erkaleli, Z.Ö. (2015). Uşak ili Ulubey ilçesinde yetişen karadutların (morus nigra L.) morfolojik, fenolojik ve pomolojik özelliklerinin belirlenmesi. (Yüksek Lisans Tezi). Bahçe Bitkileri Anabilim Dal1. 53s. 
Erkaleli, Z.Ö., \& Dalkılıç, Z. (2016). Uşak İli Ulubey İlçesinde yetişen karadutların (morus nigra L.) morfolojik, fenolojik ve pomolojik özelliklerinin belirlenmesi. .Adnan Menderes Üniversitesi Ziraat Fakültesi Dergisi. 13 (1), 89-106.

Güneş, M., \& Çekiç, Ç. (2003). Tokat yöresinde yetiştirilen farklı dut türlerinin fenolojik ve pomolojik özelliklerinin belirlenmesi. In: Ulusal Kivi ve Üzümsü Meyveler Sempozyumu Bildileri. 23-25, Ekim. Ordu.

Gündoğdu, M., Yılmaz, H., Geçer, MK., \& Kayakeser, U. (2012). Van Gölü havzasındaki dut türlerinin farklı olgunluk dönemlerindeki bazı fizikokimyasal özelliklerinin belirlenmesi. In: IV. Ulusal Üzümsü Meyveler Sem. Bildirileri. 3-5 Ekim. Antalya.

Ilgın, M., \& Ağca, İ. (2017). Türkiye'nin değişik yerlerinden selekte edilen bazı dut (Morus spp.) türlerinin Doğu Akdeniz Bölgesi’nde performanslarının belirlenmesi. Manas J AgrVet Life Sci. 7 (2), $45-57$.

İslam, A., Turan, A., Şişman, T., Kurt, H., \& Aygün, A. (2006). Giresun Şebinkarahisar' da dut seleksiyonu. In: II. Üzümsü Meyveler Sem. Bildileri. 14-16 Eylül. Tokat.

Lale, H. (1992). Dut Türlerinin Pomolojik, Fenolojik ve Bazı Meyve Kalite Özellikleri Üzerinde bir Çalısma. Ege Üniversitesi, Fen Bilimleri Enstitüsü, İzmir, $68 \mathrm{~s}$.

Özgen, M., Güneş, M., Akça, Y., Türemıs, N., Ilgın, M., Kızılcı, G., Erdoğan, Ü., \& Serçe, S. (2009). Morphological characterization of several Morus species from Turkey. Hort. Environ. Biotechnol. 50(1), 9-13.

Polat, A. (2005). Hatay'ın Antakya ilçesinde yetiştirilen bazı dut tiplerinin meyve özelliklerinin belirlenmesi.(Yüksek Lisans Tezi, basılmamış). Mustafa Kemal Üniversitesi,3 Fen Bilimleri Enstitüsü, Bahçe Bitkileri Anabilim Dalı, Hatay.

Uzun, H., \& Bayır, A. (2009). Farkl dut genotiplerinin bazı kimyasal özellikleri ve antiradikal aktiviteleri. III. Ulusal Üzümsü Meyveler Sempozyumu Bildirileri. 10-12 Haziran. Kahramanmaraş. 